\title{
BMJ Open Theoretical explanations for socioeconomic inequalities in multimorbidity: a scoping review
}

\author{
Ludmila Fleitas Alfonzo (D) , ${ }^{1}$ Tania King, ${ }^{1}$ Emily You, ${ }^{2}$ Diana Contreras-Suarez, ${ }^{3}$ \\ Syafiqah Zulkelfi, ${ }^{1}$ Ankur Singh (D) ${ }^{4}$
}

To cite: Fleitas Alfonzo L, King T, You E, et al. Theoretical explanations for socioeconomic inequalities in multimorbidity: a scoping review. BMJ Open 2022;12:e055264. doi:10.1136/ bmjopen-2021-055264

- Prepublication history and additional supplemental material for this paper are available online. To view these files, please visit the journal online (http://dx.doi.org/10.1136/ bmjopen-2021-055264)

Received 09 July 2021 Accepted 27 January 2022

\section{Check for updates}

(c) Author(s) (or their employer(s)) 2022. Re-use permitted under CC BY-NC. No commercial re-use. See rights and permissions. Published by BMJ.

${ }^{1}$ Centre for Health Equity, Melbourne School of Population and Global Health, The University of Melbourne, Melbourne, Victoria, Australia

${ }^{2}$ Academic Unit for Psychiatry of Old Age, Department of Psychiatry, The University of Melbourne Faculty of Medicine Dentistry and Health Sciences, Melbourne, Victoria, Australia ${ }^{3}$ Melbourne Institute: Applied Economic and Social Research, University of Melbourne,

Melbourne, Victoria, Australia ${ }^{4}$ Centre of Epidemiology and Biostatistics, Melbourne School of Population and Global Health, The University of Melbourne, Melbourne, Victoria, Australia

\section{Correspondence to} Ludmila Fleitas Alfonzo; ludmila.fleitasalfonzo@unimelb. edu.au

\section{ABSTRACT}

Objective To document socioepidemiological theories used to explain the relationship between socioeconomic disadvantage and multimorbidity.

Design Scoping review.

Methods A search strategy was developed and then applied to multiple electronic databases including Medline, Embase, PsychInfo, Web of Science, Scielo, Applied Social Sciences, ERIC, Humanities Index and Sociological Abstracts. After the selection of studies, data were extracted using a data charting plan. The last search was performed on the 28 September 2021. Extracted data included: study design, country, population subgroups, measures of socioeconomic inequality, assessment of multimorbidity and conclusion on the association between socioeconomic variables and multimorbidity. Included studies were further assessed on their use of theory, type of theories used and context of application. Finally, we conducted a meta-narrative synthesis to summarise the results.

Results A total of 64 studies were included in the review. Of these, 33 papers included theories as explanations for the association between socioeconomic position and multimorbidity. Within this group, 16 explicitly stated those theories and five tested at least one theory. Behavioural theories (health behaviours) were the most frequently used, followed by materialist (access to health resources) and psychosocial (stress pathways) theories. Most studies used theories as post hoc explanations for their findings or for study rationale. Supportive evidence was found for the role of material, behavioural and life course theories in explaining the relationship between social inequalities and multimorbidity.

Conclusion Given the widely reported social inequalities in multimorbidity and its increasing public health burden, there is a critical gap in evidence on pathways from socioeconomic disadvantage to multimorbidity. Generating evidence of these pathways will guide the development of intervention and public policies to prevent multimorbidity among people living in social disadvantage. Material, behavioural and life course pathways can be targeted to reduce the negative effect of low socioeconomic position on multimorbidity.

\section{INTRODUCTION}

Multimorbidity is a societal challenge and an increasingly recognised public health

\section{Strengths and limitations of this study}

This is the first scoping review exploring the use of theories to explain the association between socioeconomic position and multimorbidity.

- Our review has identified critical gaps in the literature that must be addressed if interventions and public policies are to be designed to reduce socioeconomic inequalities in multimorbidity.

- We applied a comprehensive search strategy to identify relevant articles and applied a peer-reviewed robust methodology to assess theories in studies on socioeconomic inequalities in multimorbidity.

- Articles that were not in English were excluded from our review. This could have obstructed the inclusion of papers from countries where English is not the main language, therefore limiting the generalisability of our findings.

concern. ${ }^{1-3}$ It is described as the co-occurrence of two or more chronic conditions in an individual. ${ }^{4}$ Multimorbidity leads to reduced quality of life, high psychological distress, burden of polypharmacy and managing multiple treatment protocols, and an increased risk of premature death in people. ${ }^{5}$ There is an emerging threat of increased multimorbidity worldwide, primarily due to population ageing and the epidemiological transition from communicable to non-communicable diseases. ${ }^{6}$ The COVID-19 pandemic has put a spotlight on multimorbidity as people with existing chronic conditions have suffered a higher risk of its infection, as well as more severe consequences of SARS-CoV-2 infection. ${ }^{7}$ Furthermore, multiple studies have reported socioeconomic inequalities in multimorbidity within countries regardless of their level of economic development..$^{8-12}$

A meta-analysis of 24 cross-sectional studies reported that low education compared with high education was associated with $64 \%$ higher odds of multimorbidity. ${ }^{13}$ Another systematic review with 41 studies from high-income 
countries reported that people with the lowest level of income had 4.4 times higher odds of multimorbidity than those with the highest level of income, while those in most deprived areas had 1.42 times higher odds of multimorbidity than those in the least deprived areas. ${ }^{14} \mathrm{~A}$ clear causal relationship between socioeconomic conditions and multimorbidity has also been argued based on empirical evidence; ${ }^{10}$ however, pathways through which socioeconomic disadvantage leads to multimorbidity are not well studied. ${ }^{4}$

Theories are used in epidemiology to understand the relationships between exposure to, for example, socioeconomic disadvantage and non-communicable diseases. This is mainly because, as opposed to conceptual frameworks, specific theoretical pathways can be tested using empirical data. Theories provide insight into the mechanisms through which an exposure (eg, socioeconomic position) leads to a health outcome, ${ }^{15}$ and as such, they are particularly helpful in informing intervention designs. Since the release of the Black Report in $1982,{ }^{16}$ several categories of theories have been proposed to explain associations between social inequalities and health outcomes ${ }^{1617}$ although in the context of single diseases or health measure. These include:

1. Behavioural: the behavioural explanation posits that people from different backgrounds behave differently and make health-related choices that are commonly based on their socioeconomic background. As people experience socioeconomic deprivation, they also encounter more barriers to adopting healthy lifestyles. For instance, individual health damaging and promoting behaviours are differentially distributed across the social scale, with more disadvantaged groups more likely to engage in health damaging behaviours such as smoking, and advantaged groups more likely to engage in health-promoting behaviours such as physical activity. ${ }^{18}$ As a result, poor health outcomes are commonly clustered at the lower end of the socioeconomic scale. ${ }^{17}$ Behavioural theory can be extended to apply to multimorbidity from a common risk factor approach, as a behavioural risk factor can cause multiple diseases (eg, smoking can cause cancer, asthma and cardiovascular diseases ${ }^{1920}$ ).

2. Psychosocial: this theory postulates that the emotions that arise due to social inequality can directly affect biological health. ${ }^{17}$ This can be caused in two ways, either through the practice of health compromising behaviours or through biological changes due to the individual being in a sustained state of stress. ${ }^{17}$ Hence, the behavioural explanation can be a descendent of psychosocial processes under this explanation. The perceived lack of control and psychosocial stress may lead to adverse health behaviours and may activate neuroendocrine mechanisms, and in doing so, may affect multiple body systems and lead to multimorbidity.

3. Materialist: the material environment has a significant impact on the health of an individual. Exposure to health risk or health protective factors varies according to socioeconomic position due to differential access to material resources; differences are more evident in non-egalitarian societies. For instance, individuals living in socioeconomic disadvantage are less likely to be able to access information and resources necessary to maintain good health compared with their more advantaged counterparts. ${ }^{17}$ Socioeconomically deprived individuals are also more likely to be exposed to hazardous working environments. ${ }^{17}$ The materialist theory proposes these explanations as pathways between socioeconomic deprivation and health inequalities. ${ }^{17}$ Lack of material resources such as inadequate housing, for example, can lead to multimorbidity by causing depression as well as respiratory illnesses such as asthma.

4. Social support: this theory holds that positive social support mitigates the detrimental effect of socioeconomic deprivation in health. ${ }^{21}{ }^{22}$ Accordingly, strong social networks and good social relationships are linked to good health, and conversely, poor social relations and weak social support networks are deleterious to health. Social support is considered to be a distal determinant of health that may influence health through multiple mechanisms, for example, by reducing stress and providing access to local resources, and in doing so, may prevent both mental and physical multimorbidity.

5. Social capital: while variously defined, social capital is broadly described as the functioning of social groups through a shared sense of identity, trust, cooperation, reciprocity and shared understandings, norms and values. ${ }^{23}$ Social capital emphasises that a more unequal distribution in income undermines trust and damages social relationships at a population level. This theory attempts to explain why egalitarian societies tend to be healthier than non-egalitarian societies. ${ }^{24}{ }^{25}$ Similar to social support, high social capital is likely to boost health and prevent multimorbidity by reducing stressors and increasing access to shared resources.

In addition to the above-mentioned theories, a life course framework examines the effect of early life socioeconomic exposures on later health outcomes. ${ }^{26}$ Two models are proposed to explain the life course framework: the accumulation model and the critical periods model. The accumulation model emphasises the cumulative effect of exposure to socioeconomic disadvantage across different stages in life on subsequent increased risk of poor health outcomes. ${ }^{27}$ The critical periods model focuses on the effect of exposure to factors influencing health during critical periods of development. ${ }^{27}$ Finally, a neo-liberal framework for health inequalities emphasises the role of political arrangements in leading to socioeconomic inequalities and in turn health inequalities. ${ }^{28}$

We aim to review the socioepidemiological theories applied to explain the relationship between socioeconomic disadvantage and multimorbidity in the population. Where possible, we examined whether theories applied were tested using robust analytical methods such as mediation analysis. 


\section{METHODS}

We conducted a scoping review to examine epidemiological theories applied to explain the association between socioeconomic disadvantage and multimorbidity ${ }^{29} 30$ and to map the information available in the current literature. Because the primary purpose of this study was to identify and categorise the theories being used in the existing literature, a scoping review was preferred over a systematic review. We followed the steps of a scoping review as per previously defined guidelines. ${ }^{29} 30$

\section{Stage I: identifying the research question}

Our review question was: 'How are the socio-epidemiologic theories applied to explain the relationship between socioeconomic disadvantage and multimorbidity?'.

\section{Stage II: identifying relevant studies}

We identified search terms and keywords relevant to socioeconomic disadvantage, theoretical pathways and multimorbidity from published systematic reviews ${ }^{13} 31$ and tailored them to answer our research question. First, a detailed search strategy was developed using keywords and hierarchically defined subject headings. Once the search terms were agreed on, they were adapted for multiple electronic databases including Medline, Embase, PsychInfo (Ovid platform), Web of Science, Scielo, Applied Social Sciences, ERIC, Humanities Index and Sociological Abstracts (see online supplemental appendix 1). The reference lists of all selected articles were screened to identify any additional studies. Search alerts were set up to notify the research team of articles published after 25 May 2018 when literature search was implemented. This search was updated on 11 December 2019 and then on 28 September 2021.

\section{Stage III: study selection}

We applied a strict inclusion and exclusion criteria; these are displayed in table 1 . We use the term socioeconomic position to reflect socioeconomic status of individuals or groups in the population. Socioeconomic status indicates the position in which an individual or a group is located within the social structure. It can be measured using educational attainment, income, occupation, wealth and area level measures (deprivation, socioeconomic scores). We use the term socioeconomic inequalities in health to indicate the differences in disease levels between people living with different socioeconomic positions. Socioeconomic disadvantage refers to those who have the low socioeconomic position. For inclusion in this review, socioeconomic position could be measured using the following indicators: occupation, income (household or individual), educational attainment, area level socioeconomic deprivation, wealth and social class. ${ }^{1732}$

We excluded studies on 'comorbidity' as such studies are focused on an index condition (eg, diabetes). ${ }^{33}$ The terms multimorbidity and comorbidity are often used interchangeably as both describe the presence of multiple chronic conditions. However, comorbidity is a diseasecentred term that describes the presence of additional conditions associated with an index disease. ${ }^{4}$ The focus of this review is multimorbidity only. Studies on institutionalised individuals, qualitative research and those written in a language other than English were excluded. A detailed list of inclusion and exclusion criteria can be found in table 1. Abstracts and full-text articles were reviewed for inclusion by LFA using the citation manager EndNote. A second reviewer (AS) cross-checked $10 \%$ of these articles.

\section{Stage IV: charting the data}

A data charting form was created that included study details (study design, country, population subgroups, measures of socioeconomic inequality, assessment of multimorbidity and conclusion on the association between socioeconomic variables and multimorbidity), use of theory, type of theories and context of application. Use of theory was categorised as inferred by us (reviewers/readers) or explicitly mentioned by the original study authors. It is important to distinguish between the two because the former relies on the reviewers/readers' subjective judgement (which may not be accurate), while the latter accurately reflects the theoretical reasoning of the original authors. Data charting was performed by LFA and $10 \%$ of the studies were cross checked by AS.

Each study was examined for the type of theory (example: psychosocial or material), extent of use (whether used in a post hoc manner or integrated within an analysis) and their context of use (background, methods or discussion section of retrieved paper(s)). We recorded whether theories that were directly mentioned or inferred were consistent with any of the existing socioepidemiological

Table 1 Study selection criteria

\begin{tabular}{ll}
\hline Inclusion criteria & Exclusion criteria \\
\hline Studies with participants from any age group. & Studies on institutionalised individuals. \\
Community representative participants. & Studies on comorbidity. \\
Individual and population-based epidemiological studies & Qualitative studies. \\
looking at the association between socioeconomic & Study protocols, editorials and commentaries that do not \\
disadvantage and multimorbidity. & report on association between social disadvantage and \\
Intervention studies involving examining moderators or & multimorbidity. \\
mediators derived from theoretical constructs. & Literature reviews, scoping reviews and systematic reviews. \\
Studies in English language. & \\
\hline
\end{tabular}


theories. When directly mentioned, types of theories were recorded verbatim. This follows the approach previously applied in a published study examining the application of socioepidemiological theories in studies on the relationship between social inequality and oral health. ${ }^{31}$

\section{Stage V: collating, summarising and reporting the results}

We carried out a narrative synthesis to summarise the results from the retrieved data. Because the objective of this review is to offer a snapshot of the available evidence of theories explaining socioeconomic inequalities in multimorbidity and not on assessing the effect of socioeconomic disadvantage on multimorbidity development, we did not assess the quality of included papers in accordance with the guidelines for conducing scoping reviews. ${ }^{29}$

\section{Patient and public involvement}

No patients were directly involved in this study as this is a review of published studies.

\section{RESULTS}

Our initial search led to the identification of 751 unique papers that underwent title and abstract screening. Sixtynine papers were deemed eligible for full-text review. In addition, two studies were included for full-text review from other sources. Thirty-six studies proceeded to data charting stage after completion of full-text review. Online supplemental appendix 2 displays a list of studies with reasons for exclusion after full-text review. The updated search on 28 September 2021 led to a further screening of 461 titles and abstracts from the 573 newly identified records. After full-text screening of 44 studies, 27 new studies were included in the review. A total of 64 studies were included in this review. A flow chart of this process is shown in figure 1.

\section{Summary characteristics of included studies}

Twenty studies were from low-income and middle-income countries $^{12}{ }^{34-52}$ and the remaining 45 studies were from high-income countries. The majority of articles were conducted among adults and only three study included children. ${ }^{53-55}$ More than half $(n=38 / 64)$ were crosssectional and 26/64 used longitudinal data ${ }^{9} 10425456-76$ (table 2).

Educational attainment was the preferred measure of socioeconomic position $(\mathrm{n}=38 / 64)$, and 38 studies used multiple measures of socioeconomic position as exposures. The majority of studies $(n=51 / 64)$ simply documented the presence of multimorbidity, and approximately onethird $(n=13 / 64)$ additionally examined different patterns of multimorbidity ${ }^{9} 40414547535567-7072757778$ (table 2).

\section{Types of theories}

Overall, nearly half of studies (33/64) referred to at least one socioepidemiological theory. Therefore, 31 studies can be considered largely atheoretical, without any emphasis on pathways through which socioeconomic disadvantage leads to multimorbidity. In the 33 studies applying a theory, the following theories were referred to: behavioural, ${ }^{10} 3435373840-424651-53597172$ 79-82 materialist $^{38} 414245464850527172747982-85$ and psychosocial. ${ }^{34} 4251525772738284-86$ In addition, four studies applied a theoretical construct called 'sense of coherence', which indicates an individual's coping capacity to deal with life and stressful events, ${ }^{87}$ and is an indicator of self-efficacy and psychosocial well-being (consistent with psychosocial explanations) ${ }^{73}$ and also encompasses social capital ${ }^{51}$ and social support, ${ }^{57}$ which are widely considered as

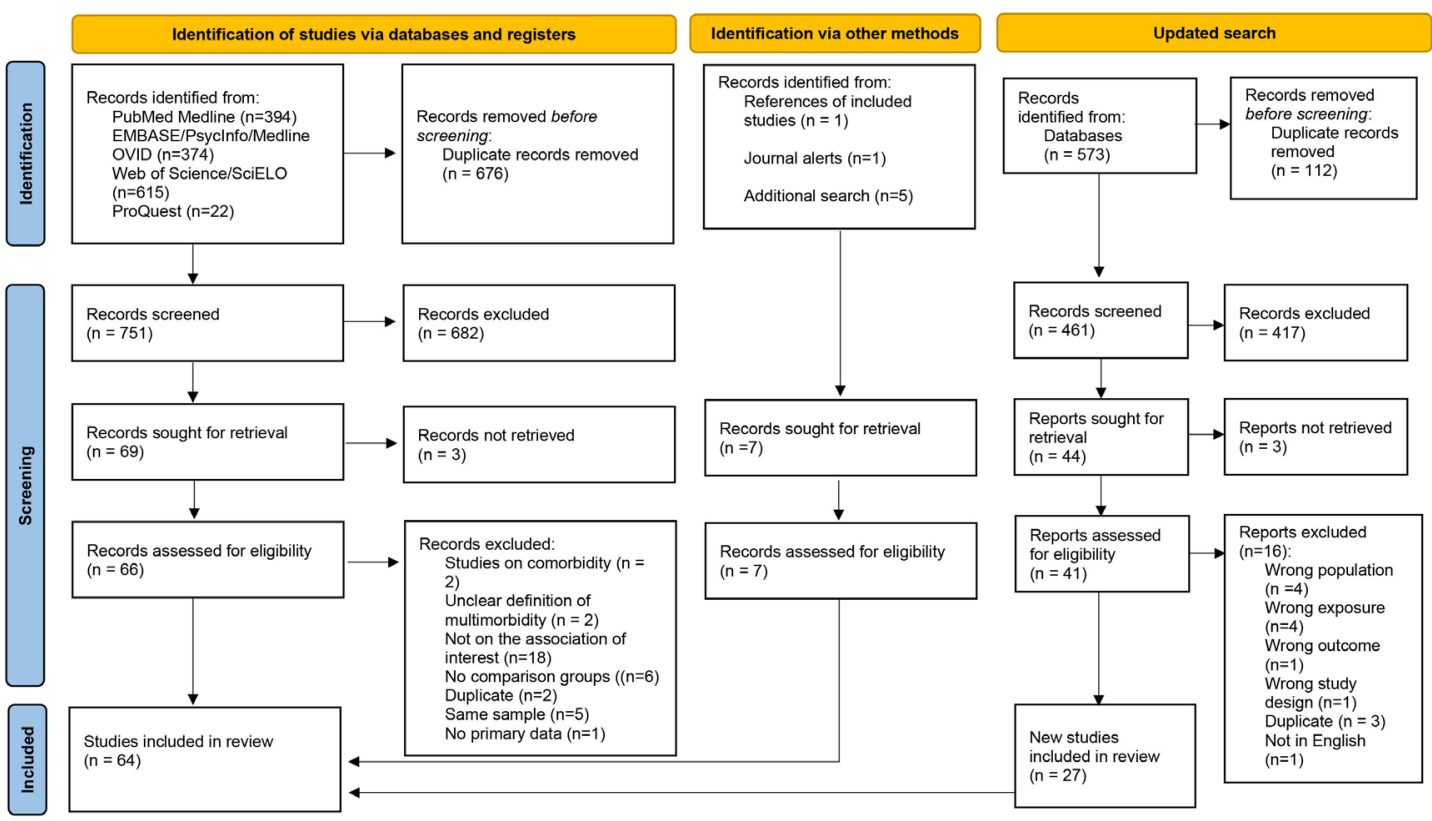

Figure 1 Flow chart of the study selection process. 

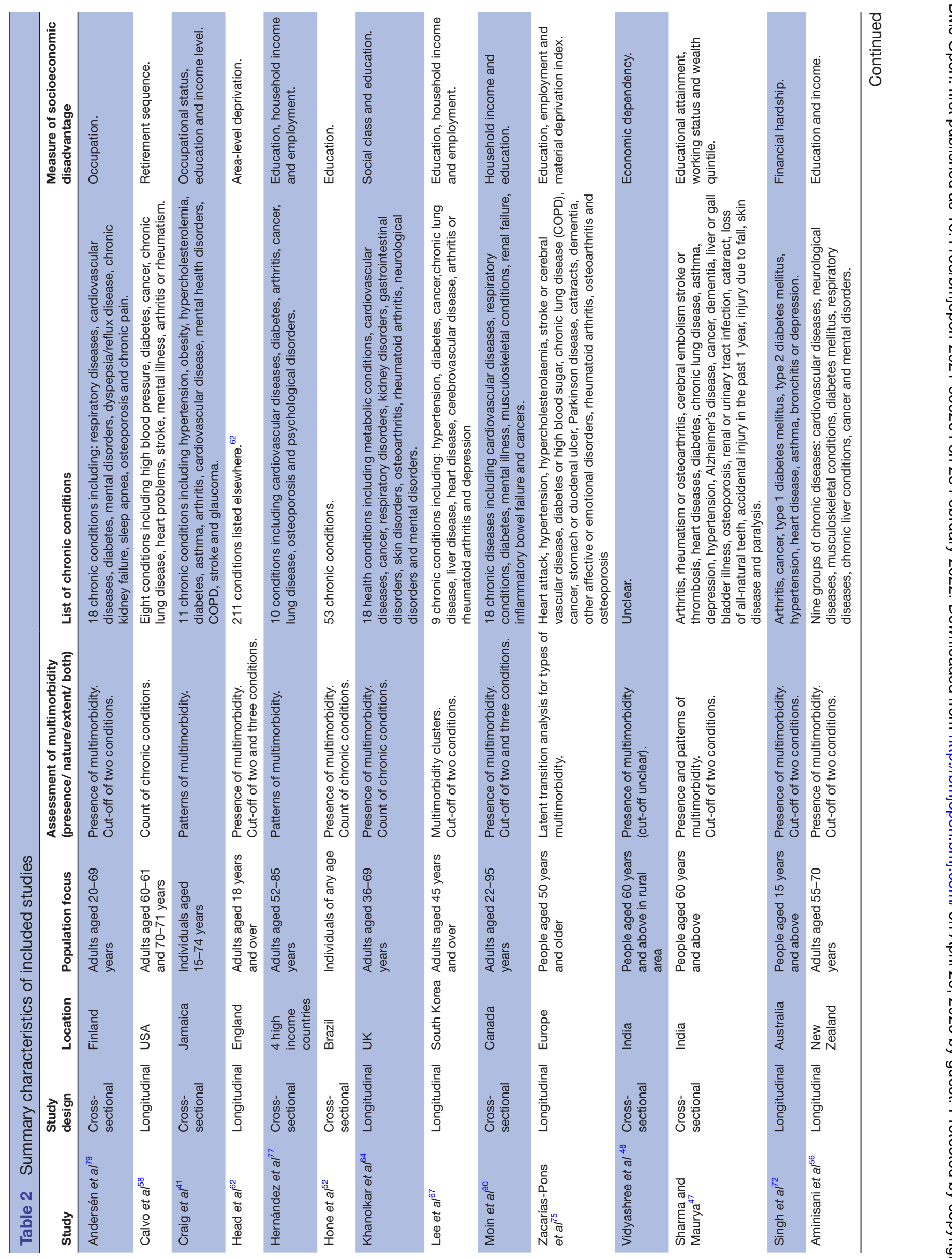

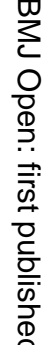




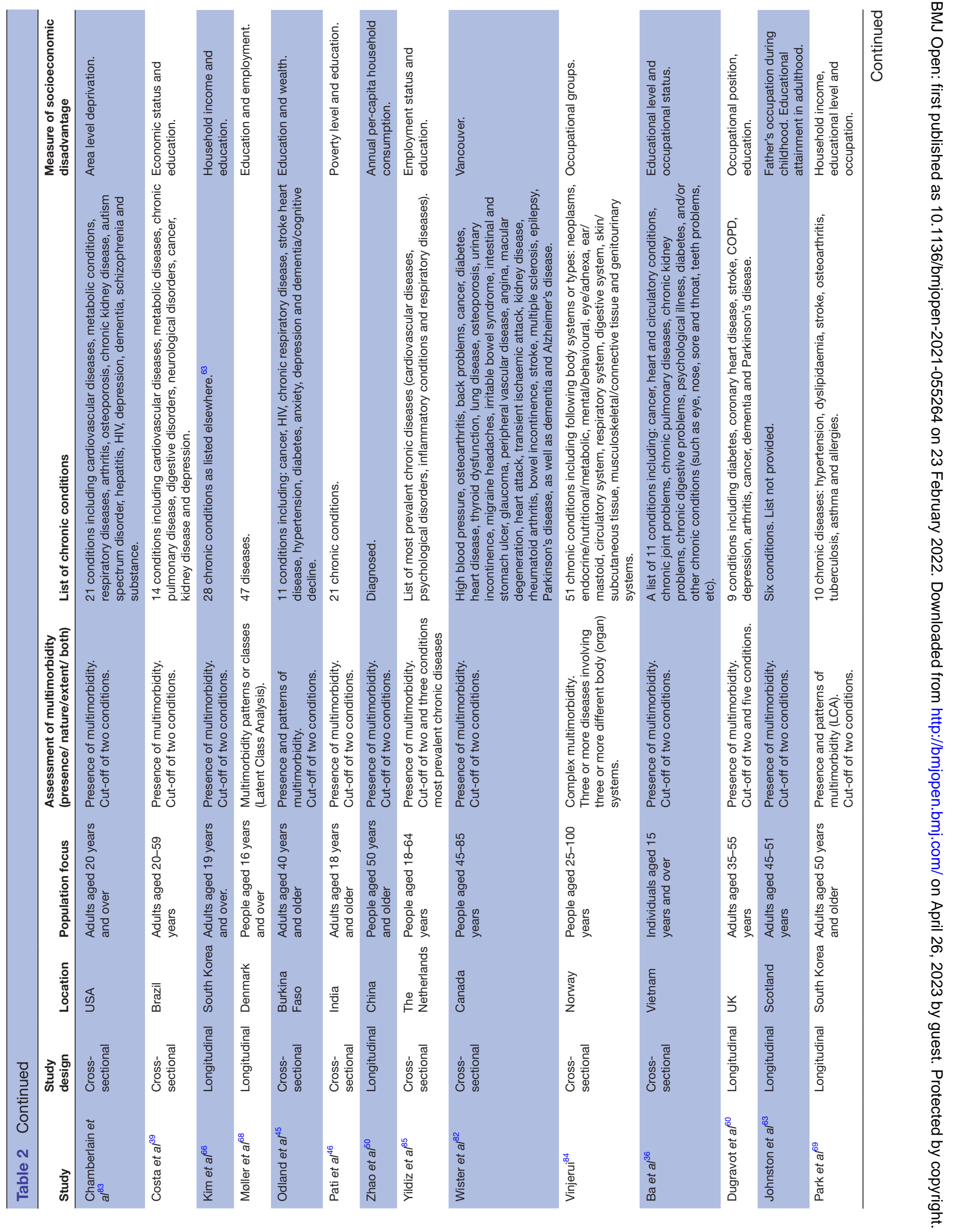




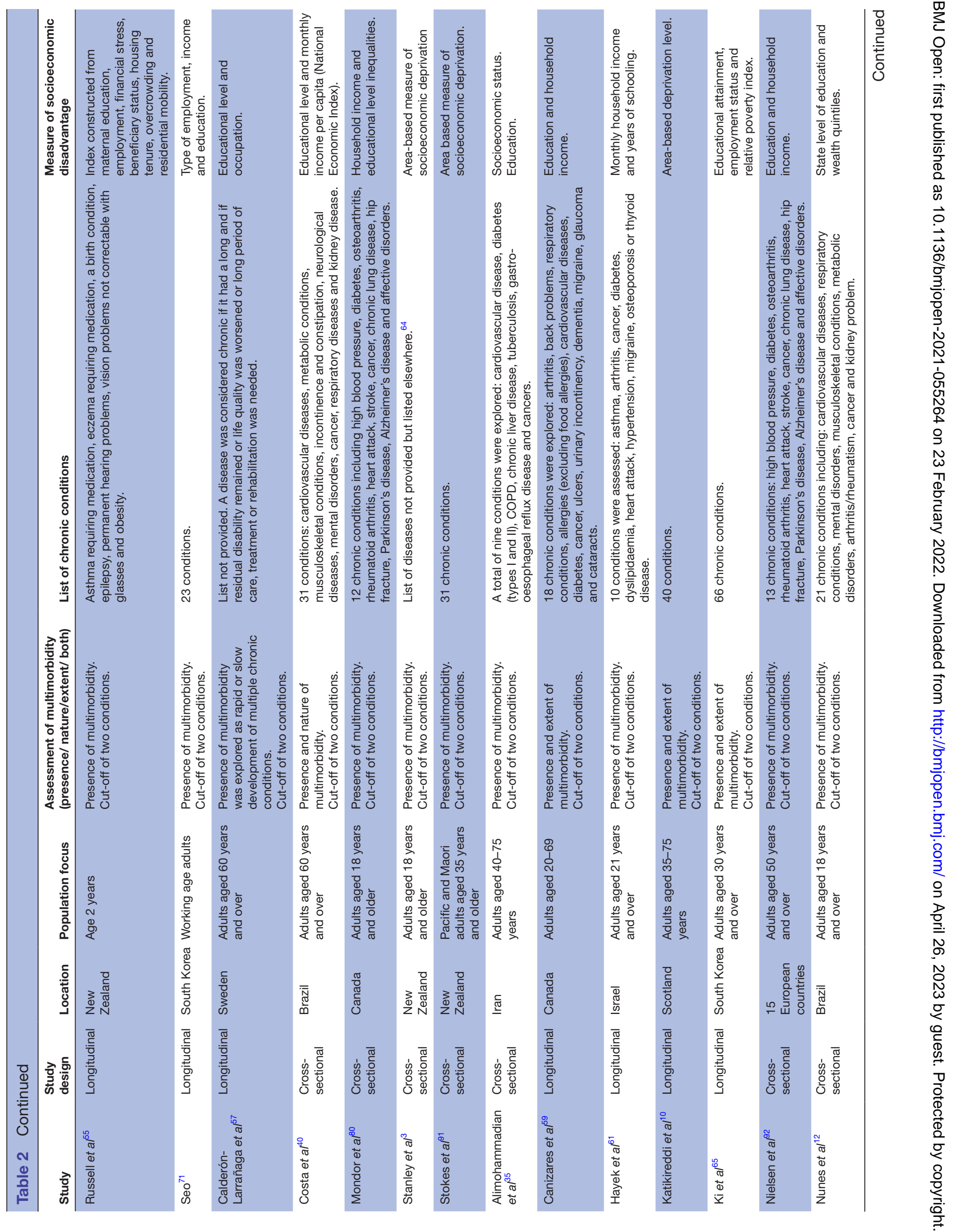



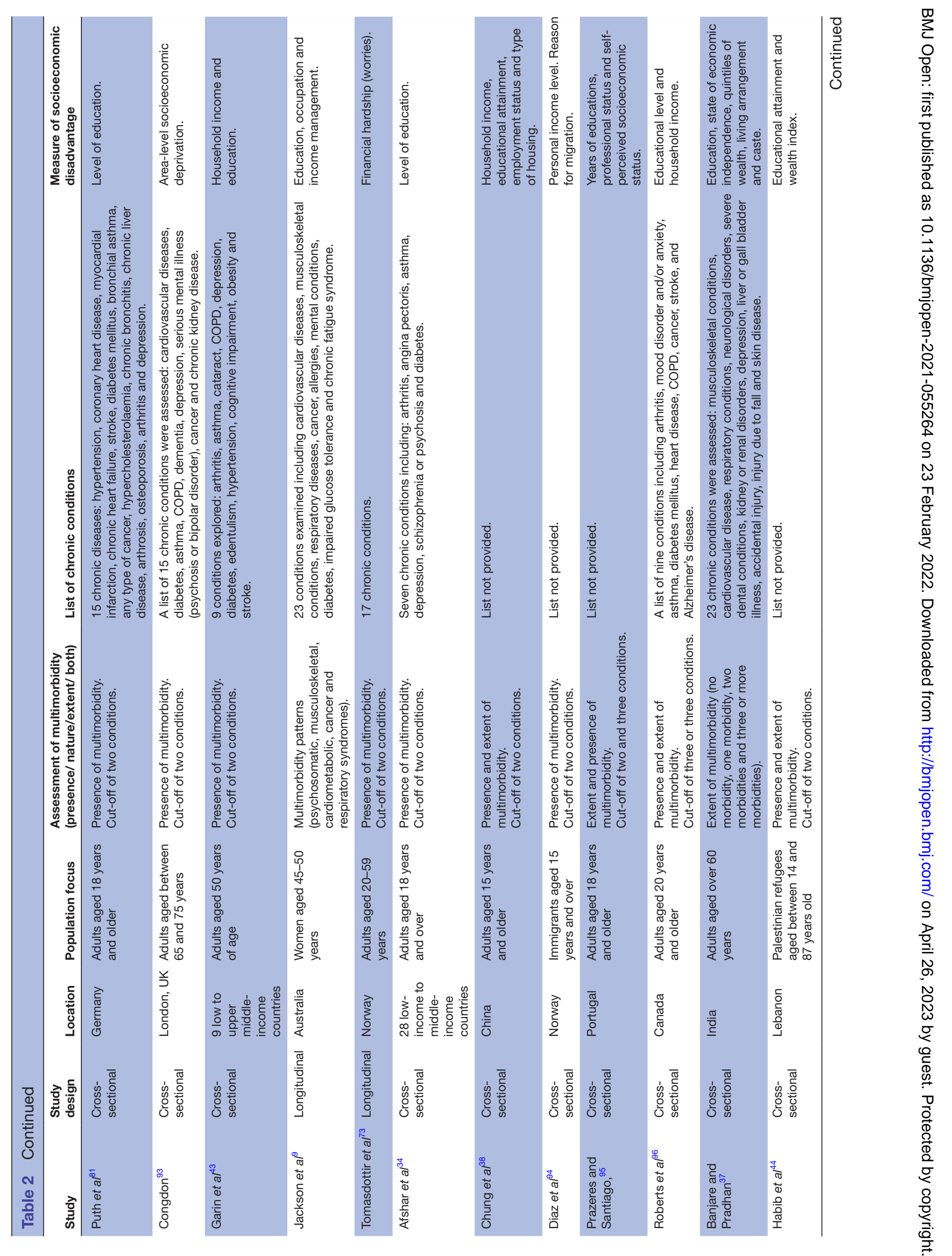


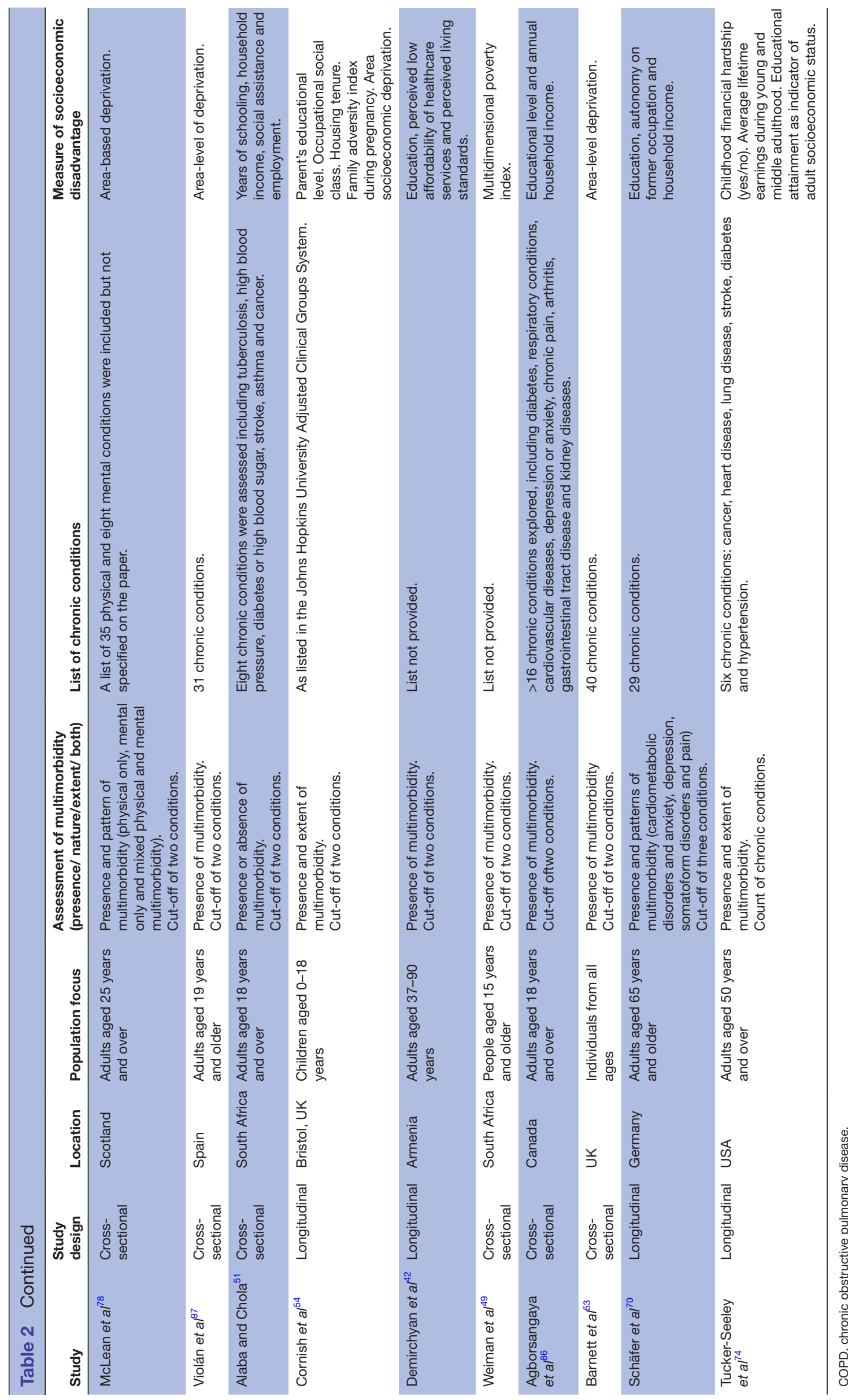


psychosocial assets (table 3). Five studies used a life-course framework. ${ }^{1055636474}$ Collectively, behavioural theory was the most referred to among studies.

\section{Context of application of theories}

Of the papers using theories, 15 explicitly stated those theories, ${ }^{10} 35384157636472-74808284-86$ and the other 21 studies were inferred to be consistent with a presumed theoretical pathway, based on definitions from existing literature.

\section{Testing the explanatory potential of theories}

Only five studies ${ }^{10} 38637280$ tested variables consistent with theoretical pathways as mediators between socioeconomic disadvantage and multimorbidity. Applying material theory, Chung et $a l^{38}$ examined perceptions of financial hardship, an indicator of economic deprivation, as a mediator between housing tenure and multimorbidity. They found a small mediation effect $(1.41 \%)$, indicating that increased financial burden puts private housing residents at a higher risk of suffering multimorbidity when compared with public housing residents. ${ }^{38}$

Drawing on behavioural theory as well as a life course framework, Katikireddi $e t a l^{10}$ quantified mediation by five behavioural risk factors (diet, smoking, physical activity, alcohol and body mass index (BMI)) acting on the association between two socioeconomic measures (area-based deprivation and household income) and multimorbidity over the life course. Their analyses showed that the combination of behavioural factors partially mediated (by $40.8 \%$ ) the inverse association between area level deprivation and multimorbidity.

The life course framework was applied by Johnston $e t$ $a b^{63}$ in their examination of educational attainment during adulthood as a mediator of the association between father's occupational social class at birth and multimorbidity. Their analyses showed a partial attenuation of the effect of childhood socioeconomic position on multimorbidity by educational attainment. Authors did not report the proportion of effect that was mediated by adult educational attainment.

Mondor $e t a l^{80}$ also drew on behavioural theory in their study that quantified the mediation effect of lifestyle factors (physical activity, smoking and BMI) on the association between income inequalities and multimorbidity. Lifestyle factors only explained a small proportion of observed income-related inequalities in multimorbidity. Physical activity explained $10.9 \%$ of income inequalities, while smoking and BMI only accounted for $1.8 \%$ and $0.4 \%$, respectively.

Finally, Singh $e t a l^{2}$ examined social support as a mediator between financial hardship and multimorbidity among Australian adults and found that $30 \%$ of the total effect of financial hardship on multimorbidity was transmitted through social support.

\section{DISCUSSION}

\section{Summary of findings}

Overall, we found limited use of theories to explain the relationship between socioeconomic position and multimorbidity. When used, theories were seldom explicitly mentioned or tested. Among all the potential explanations, behavioural theories were the most frequently used, followed by materialist and then psychosocial theories.

Only five studies tested the explanatory potential of theories and their mediation effect on the association between socioeconomic position and multimorbidity. Although we identified the use of seven different theories, materialist, behavioural, psychosocial and life course theories were the only ones tested. Existing evidence partially support these theories ${ }^{10} 38637280$; however, their use was mostly limited to post hoc explanations of findings in the overall literature.

Our findings are consistent with the two major evidence gaps highlighted in the report 'Multimorbidity: a priority for global health research'. ${ }^{4}$ First, evidence of the relationship between socioeconomic disadvantage and multimorbidity is largely cross-sectional. This is a limitation of the existing evidence, as temporal ordering between exposure (social disadvantage) and outcome (multimorbidity), a key undisputed criterion of causality ${ }^{88}$ is difficult to establish cross-sectionally. Second, there is a paucity of evidence regarding pathways (eg, behavioural, material and psychosocial) between the shared causal factor (exposure to socioeconomic disadvantage) and multiple conditions that co-occur in multimorbidity. ${ }^{4}$ The lack of evidence precludes policymakers from intervening on causal mechanisms that can prevent or mitigate observed socioeconomic inequalities in multimorbidity. ${ }^{89}$ Among those studies testing theories, there was a predominance of the application of the behavioural theory. However, the use of contemporary approaches to causal inference, using a counterfactual framework to maximise exchangeability between exposed and unexposed participants, was limited. ${ }^{72}{ }^{89}$ Therefore, we cannot rule out bias arising from mediator-outcome confounding, time varying confounding or the presence exposure-outcome interaction. Approaches need to shift towards a more comprehensive examination of pathways to allow policymakers to select interventions with maximum capacity to reduce inequalities. It is also worth noting that given the variations in the relationship of interest according to individual (eg, age) and contextual characteristics (eg, country level of income development), future studies should examine the relevance of theories across different contexts and age groups.

\section{Strengths and limitations}

Our study has some strengths and limitations. To our knowledge, this is the first scoping review that explores the use of theories to explain the association between socioeconomic position and multimorbidity in the current literature. We identified numerous gaps in the literature that need to be addressed to improve our understanding of the socioeconomic inequalities in multimorbidity. Our search strategy drew on a wide range of electronic databases, and we used a robust methodology, already piloted and verified in previous work. ${ }^{31} \mathrm{~A}$ key limitation is that 


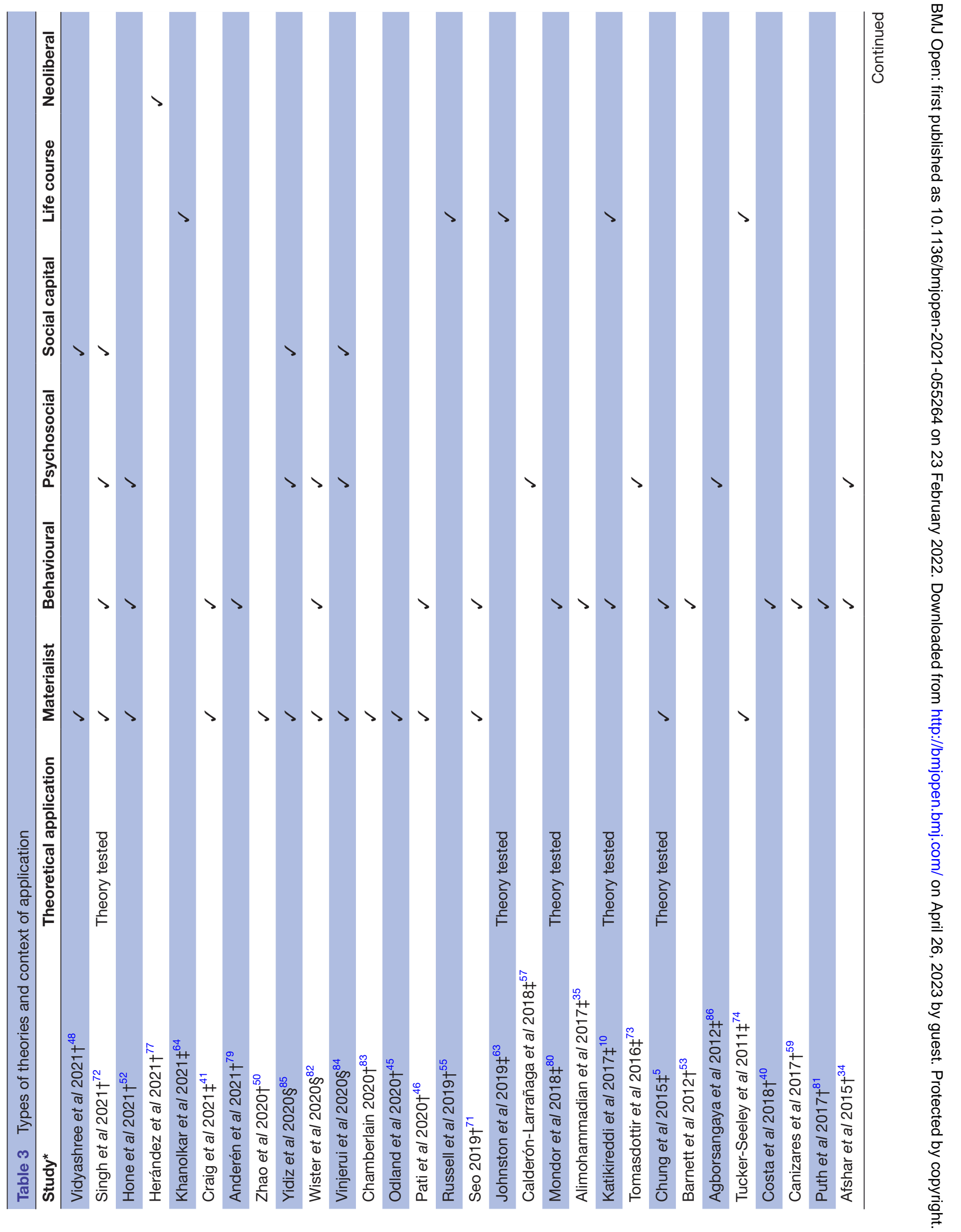




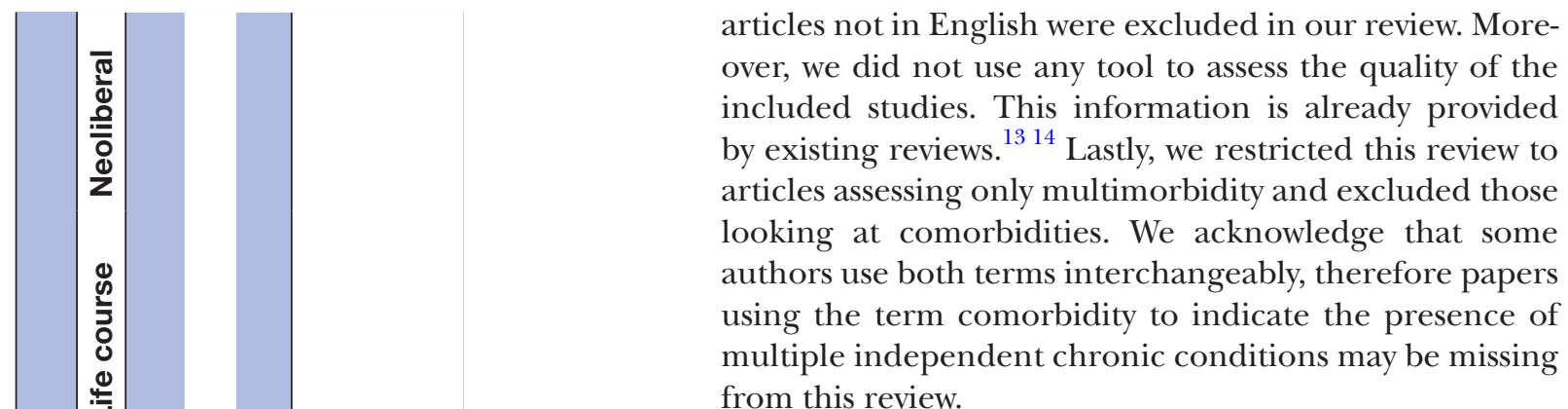
from this review.

\section{CONCLUSION}

Our understanding of the pathways between socioeconomic inequalities and multimorbidity is limited and mostly unexplained. Studies often focus on the patterns of distribution of multimorbidity across the population, rather than the mechanisms shaping these distributions. Robust evidence from longitudinal and interventional studies is needed to understand the pathways between socioeconomic disadvantage and multimorbidity. Generating such evidence will guide the development of interventions and public policies to prevent multimorbidity among people living in disadvantage.

Contributors LFA contributed towards the development of search strategy, screening, data extraction and appraisal of included studies and manuscript preparation. AS contributed towards the design, development of search strategy, screening, data extraction and appraisal of included studies and manuscript preparation. EY contributed towards the development of search strategy, data extraction of included studies and manuscript preparation. TK and DC-S contributed towards the development of search strategy and manuscript preparation. SZ contributed towards manuscript preparation. LFA and AS are the guarantors.

Funding TK is also supported by an Australian Research Council Discovery Early Career Research Award (DE200100607).

Competing interests None declared.

Patient consent for publication Not applicable.

Ethics approval This study does not involve human participants.

Provenance and peer review Not commissioned; externally peer reviewed.

Data availability statement All data relevant to the study are included in the article or uploaded as supplementary information.

Supplemental material This content has been supplied by the author(s). It has not been vetted by BMJ Publishing Group Limited (BMJ) and may not have been peer-reviewed. Any opinions or recommendations discussed are solely those of the author(s) and are not endorsed by BMJ. BMJ disclaims all liability and responsibility arising from any reliance placed on the content. Where the content includes any translated material, BMJ does not warrant the accuracy and reliability of the translations (including but not limited to local regulations, clinical guidelines, terminology, drug names and drug dosages), and is not responsible for any error and/or omissions arising from translation and adaptation or otherwise.

Open access This is an open access article distributed in accordance with the Creative Commons Attribution Non Commercial (CC BY-NC 4.0) license, which permits others to distribute, remix, adapt, build upon this work non-commercially, and license their derivative works on different terms, provided the original work is properly cited, appropriate credit is given, any changes made indicated, and the use is non-commercial. See: http://creativecommons.org/licenses/by-nc/4.0/.

ORCID iDs

Ludmila Fleitas Alfonzo http://orcid.org/0000-0001-6988-5036

Ankur Singh http://orcid.org/0000-0003-1336-6493 


\section{REFERENCES}

$1 \mathrm{Xu}$ X, Mishra GD, Dobson AJ, et al. Progression of diabetes, heart disease, and stroke multimorbidity in middle-aged women: a 20-year cohort study. PLoS Med 2018;15:e1002516.

2 Tran J, Norton R, Conrad N, et al. Patterns and temporal trends of comorbidity among adult patients with incident cardiovascular disease in the UK between 2000 and 2014: a population-based cohort study. PLoS Med 2018;15:e1002513.

3 Stanley J, Semper K, Millar E, et al. Epidemiology of multimorbidity in New Zealand: a cross-sectional study using national-level hospital and pharmaceutical data. BMJ Open 2018;8:e021689.

4 The Academy of Medical Sciences. Multimorbidity: a priority for global health research. London: The Academy of Medical Sciences, 2018.

5 Wallace E, Salisbury C, Guthrie B, et al. Managing patients with multimorbidity in primary care. BMJ 2015;350:h176.

6 Kingston A, Robinson L, Booth $\mathrm{H}$, et al. Projections of multimorbidity in the older population in England to 2035: estimates from the population ageing and care simulation (PACSim) model. Age Ageing 2018;47:374-80.

7 laccarino G, Grassi G, Borghi C, et al. Age and multimorbidity predict death among COVID-19 patients. Hypertension 2020;76:366-72.

8 Ataguba JE-O. Inequalities in multimorbidity in South Africa. Int $J$ Equity Health 2013;12:64.

9 Jackson CA, Dobson AJ, Tooth LR, et al. Lifestyle and socioeconomic determinants of multimorbidity patterns among midaged women: a longitudinal study. PLoS One 2016;11:e0156804.

10 Katikireddi SV, Skivington K, Leyland $\mathrm{AH}$, et al. The contribution of risk factors to socioeconomic inequalities in multimorbidity across the lifecourse: a longitudinal analysis of the Twenty-07 cohort. BMC Med 2017;15:152.

11 Kunna R, San Sebastian M, Stewart Williams J. Measurement and decomposition of socioeconomic inequality in single and multimorbidity in older adults in China and Ghana: results from the who study on global ageing and adult health (SAGE). Int J Equity Health 2017;16:79.

12 Nunes BP, Chiavegatto Filho ADP, Pati S, et al. Contextual and individual inequalities of multimorbidity in Brazilian adults: a crosssectional national-based study. BMJ Open 2017;7:e015885.

13 Pathirana TI, Jackson CA. Socioeconomic status and multimorbidity: a systematic review and meta-analysis. Aust N Z J Public Health 2018;42:186-94.

14 Ingram E, Ledden S, Beardon S, et al. Household and area-level social determinants of multimorbidity: a systematic review. $J$ Epidemiol Community Health 2021;75:232-41.

15 Arcaya MC, Arcaya AL, Subramanian SV. Inequalities in health: definitions, concepts, and theories. Glob Health Action 2015;8:27106.

16 Townsend P, Davidson N, Black DS. Inequalities in health : the Black report. In: Townsend P, Davidson N, Black DS, eds. Great Britain Working group on inequalities in $\mathrm{H}$. Harmondsworth: Penguin, 1982

17 Bartley M. Health inequality : an introduction to theories, concepts, and methods. Cambridge, UK: Polity Press, 2004.

18 Ball K, Timperio A, Salmon J, et al. Personal, social and environmental determinants of educational inequalities in walking: a multilevel study. J Epidemiol Community Health 2007;61:108-14.

19 Pan A, Wang Y, Talaei M, et al. Relation of smoking with total mortality and cardiovascular events among patients with diabetes mellitus: a meta-analysis and systematic review. Circulation 2015;132:1795-804.

20 Hughes K, Bellis MA, Hardcastle KA, et al. The effect of multiple adverse childhood experiences on health: a systematic review and meta-analysis. Lancet Public Health 2017;2:e356-66.

21 House JS, Landis KR, Umberson D. Social relationships and health. Science 1988;241:540-5.

22 Shumaker SA, Brownell A. Toward a theory of social support: closing conceptual gaps. J Soc Issues 1984;40:11-36.

23 Baum FE, Ziersch AM. Social capital. J Epidemiol Community Health 2003;57:320-3.

24 Kawachi I, Berkman L. Social cohesion, social capital, and health. Social epidemiology 2000;174.

25 Kawachi I, Kennedy BP. Health and social cohesion: why care about income inequality? BMJ 1997;314:1037-40.

26 Krieger N. A glossary for social epidemiology. J Epidemiol Community Health 2001;55:693-700.

27 Kawachi I, Subramanian SV, Almeida-Filho N. A glossary for health inequalities. J Epidemiol Community Health 2002;56:647-52.

28 Coburn D. Income inequality, social cohesion and the health status of populations: the role of neo-liberalism. Soc Sci Med 2000;51:135-46.

29 Levac D, Colquhoun H, O'Brien KK. Scoping studies: advancing the methodology. Implement Sci 2010;5:69.
30 Arksey H, O'Malley L. Scoping studies: towards a methodological framework. Int J Soc Res Methodol 2005;8:19-32.

31 Singh A, Harford J, Schuch HS, et al. Theoretical basis and explanation for the relationship between area-level social inequalities and population oral health outcomes - A scoping review. SSM Popul Health 2016;2:451-62.

32 American Psychological Association. Measuring socioeconomic status and subjective social status. public interest Directorate, socioeconomic status office, resources and publication 2018.

33 Bonavita V, De Simone R. Towards a definition of comorbidity in the light of clinical complexity. Neurol Sci 2008;29 Suppl 1:S99-102.

34 Afshar S, Roderick PJ, Kowal P, et al. Multimorbidity and the inequalities of global ageing: a cross-sectional study of 28 countries using the world health surveys. BMC Public Health 2015;15:776.

35 Alimohammadian M, Majidi A, Yaseri M, et al. Multimorbidity as an important issue among women: results of a gender difference investigation in a large population-based cross-sectional study in West Asia. BMJ Open 2017;7:e013548.

36 Ba NV, Minh HV, Quang LB, et al. Prevalence and correlates of multimorbidity among adults in border areas of the central highland region of Vietnam, 2017. J Comorb 2019;9:2235042X19853382.

37 Banjare P, Pradhan J. Socio-Economic inequalities in the prevalence of multi-morbidity among the rural elderly in Bargarh district of Odisha (India). PLoS One 2014;9:e97832.

38 Chung RY, Mercer S, Lai FTT, et al. Socioeconomic determinants of multimorbidity: a population-based household survey of Hong Kong Chinese. PLoS One 2015;10:e0140040.

39 Costa Ândria Krolow, Bertoldi AD, Fontanella AT, et al. Does socioeconomic inequality occur in the multimorbidity among Brazilian adults? Rev Saude Publica 2020:54:138.

40 Costa CDS, Flores TR, Wendt A, et al. Inequalities in multimorbidity among elderly: a population-based study in a City in southern Brazil. Cad Saude Publica 2018;34:e00040718.

41 Craig LS, Cunningham-Myrie CA, Hotchkiss DR, et al. Social determinants of multimorbidity in Jamaica: application of latent class analysis in a cross-sectional study. BMC Public Health 2021;21:1197.

42 Demirchyan A, Khachadourian V, Armenian HK, et al. Short and long term determinants of incident multimorbidity in a cohort of 1988 earthquake survivors in Armenia. Int J Equity Health 2013;12:68.

43 Garin N, Koyanagi A, Chatterji S, et al. Global multimorbidity patterns: a cross-sectional, population-based, Multi-Country study. J Gerontol A Biol Sci Med Sci 2016;71:205-14.

44 Habib RR, Hojeij S, Elzein K, et al. Associations between life conditions and multi-morbidity in marginalized populations: the case of Palestinian refugees. Eur J Public Health 2014;24:727-33.

45 Odland ML, Payne C, Witham MD, et al. Epidemiology of multimorbidity in conditions of extreme poverty: a populationbased study of older adults in rural Burkina Faso. BMJ Glob Health 2020;5:e002096.

46 Pati S, Swain S, Knottnerus JA, et al. Magnitude and determinants of multimorbidity and health care utilization among patients attending public versus private primary care: a cross-sectional study from Odisha, India. Int J Equity Health 2020;19:57

47 Sharma P, Maurya P. Gender differences in the prevalence and pattern of disease combination of chronic multimorbidity among Indian elderly. Ageing Int 2021;14

48 Vidhyashree MD, Adhilakshmi R, Kamini B. Socio-Economic determinants of multimorbidity among the elderly population in a rural area in Kancheepuram district of Tamil Nadu. Journal of Research in Medical and Dental Science 2021:9:436-41.

49 Weimann A, Dai D, Oni T. A cross-sectional and spatial analysis of the prevalence of multimorbidity and its association with socioeconomic disadvantage in South Africa: a comparison between 2008 and 2012. Soc Sci Med 2016;163:144-56.

50 Zhao Y, Atun R, Oldenburg B, et al. Physical multimorbidity, health service use, and catastrophic health expenditure by socioeconomic groups in China: an analysis of population-based panel data. Lancet Glob Health 2020;8:e840-9.

51 Alaba O, Chola L. The social determinants of multimorbidity in South Africa. Int J Equity Health 2013;12:63.

52 Hone T, Stokes J, Trajman A, et al. Racial and socioeconomic disparities in multimorbidity and associated healthcare utilisation and outcomes in Brazil: a cross-sectional analysis of three million individuals. BMC Public Health 2021;21:1287.

53 Barnett K, Mercer SW, Norbury M, et al. Epidemiology of multimorbidity and implications for health care, research, and medical education: a cross-sectional study. Lancet 2012;380:37-43.

54 Cornish RP, Boyd A, Van Staa T, et al. Socio-Economic position and childhood multimorbidity: a study using linkage between the Avon longitudinal study of parents and children and the general practice research database. Int J Equity Health 2013;12:66. 
55 Russell J, Grant CC, Morton SMB. Multimorbidity in early childhood and socioeconomic disadvantage: findings from a large New Zealand child cohort. Acad Pediatr 2020;20:619-27.

56 Aminisani N, Stephens C, Allen J, et al. Socio-Demographic and lifestyle factors associated with multimorbidity in New Zealand. Epidemiol Health 2020;42:e2020001.

57 Calderón-Larrañaga A, Santoni G, Wang HX, et al. Rapidly developing multimorbidity and disability in older adults: does social background matter? J Intern Med 2018;283:489-99.

58 Calvo E, Azar A, Shura R, et al. A new path to address multimorbidity? longitudinal analyses of retirement sequences and chronic diseases in old age. J App/ Gerontol 2021:7334648211031038.

59 Canizares M, Hogg-Johnson S, Gignac MAM, et al. Increasing trajectories of multimorbidity over time: birth cohort differences and the role of changes in obesity and income. J Gerontol B Psychol Sci Soc Sci 2018;73:1303-14.

60 Dugravot A, Fayosse A, Dumurgier J, et al. Social inequalities in multimorbidity, frailty, disability, and transitions to mortality: a 24year follow-up of the Whitehall II cohort study. Lancet Public Health 2020:5:e42-50.

61 Hayek S, Ifrah A, Enav T, et al. Prevalence, correlates, and time trends of multiple chronic conditions among Israeli adults: estimates from the Israeli National health interview survey, 2014-2015. Prev Chronic Dis 2017;14:E64.

62 Head A, Fleming K, Kypridemos C, et al. Inequalities in incident and prevalent multimorbidity in England, 2004-19: a population-based, descriptive study. The Lancet Healthy Longevity 2021;2:e489-97.

63 Johnston MC, Black C, Mercer SW, et al. Impact of educational attainment on the association between social class at birth and multimorbidity in middle age in the Aberdeen children of the 1950s cohort study. BMJ Open 2019;9:e024048.

64 Khanolkar AR, Chaturvedi N, Kuan V, et al. Socioeconomic inequalities in prevalence and development of multimorbidity across adulthood: a longitudinal analysis of the MRC 1946 national survey of health and development in the UK. PLoS Med 2021;18:e1003775.

$65 \mathrm{Ki} \mathrm{M}$, Lee YH, Kim Y-S, et al. Socioeconomic inequalities in health in the context of multimorbidity: a Korean panel study. PLOS One 2017;12:e0173770.

$66 \mathrm{Kim}$ J, Keshavjee S, Atun R. Trends, patterns and health consequences of multimorbidity among South Korea adults: analysis of nationally representative survey data 2007-2016. J Glob Health 2020;10:020426.

67 Lee SA, Joo S, Chai HW, et al. Patterns of multimorbidity trajectories and their correlates among Korean older adults. Age Ageing 2021;50:1336-41.

68 Møller SP, Laursen B, Johannesen CK, et al. Patterns of multimorbidity and demographic profile of latent classes in a Danish population-A register-based study. PLoS One 2020;15:e0237375.

69 Park B, Lee HA, Park H. Use of latent class analysis to identify multimorbidity patterns and associated factors in Korean adults aged 50 years and older. PLoS One 2019;14:e0216259.

70 Schäfer I, Hansen H, Schön G, et al. The influence of age, gender and socio-economic status on multimorbidity patterns in primary care. first results from the multicare cohort study. BMC Health Serv Res 2012:12:89.

71 Seo S. Multimorbidity development in working people. Int J Environ Res Public Health 2019;16:4749.

72 Singh A, Contreras Suarez D, You E, et al. Role of social support in the relationship between financial hardship and multimorbidity-a causal mediation analysis. Eur J Public Health 2021;31:482-7.

73 Tomasdottir MO, Sigurdsson JA, Petursson H, et al. Does 'existential unease' predict adult multimorbidity? Analytical cohort study on embodiment based on the Norwegian HUNT population. BMJ Open 2016;6:e012602.

74 Tucker-Seeley RD, Li Y, Sorensen G, et al. Lifecourse socioeconomic circumstances and multimorbidity among older adults. BMC Public Health 2011;11:313.

75 Zacarías-Pons L, Vilalta-Franch J, Turró-Garriga O, et al Multimorbidity patterns and their related characteristics in European older adults: a longitudinal perspective. Arch Gerontol Geriatr 2021:95:104428.
76 Zou S, Wang Z, Bhura M, et al. Prevalence and associated socioeconomic factors of multimorbidity in ten regions of China: a cross-sectional analysis. The Lancet 2020;396:S12.

77 Hernández B, Voll S, Lewis NA, et al. Comparisons of disease cluster patterns, prevalence and health factors in the USA, Canada, England and ireland. BMC Public Health 2021;21:1674

78 McLean G, Gunn J, Wyke S, et al. The influence of socioeconomic deprivation on multimorbidity at different ages: a cross-sectional study. Br J Gen Pract 2014;64:e440-7.

79 Andersén H, Kankaanranta H, Tuomisto LE, et al. Multimorbidity in Finnish and Swedish speaking Finns; association with daily habits and socioeconomic status - Nordic EpiLung cross-sectional study. Prev Med Rep 2021:22:101338.

80 Mondor L, Cohen D, Khan Al, et al. Income inequalities in multimorbidity prevalence in Ontario, Canada: a decomposition analysis of linked survey and health administrative data. Int $J$ Equity Health 2018;17:90.

81 Puth M-T, Weckbecker K, Schmid M, et al. Prevalence of multimorbidity in Germany: impact of age and educational level in a cross-sectional study on 19,294 adults. BMC Public Health 2017;17:826.

82 Wister A, Rosenkrantz L, Shashank A, et al. Multimorbidity and socioeconomic deprivation among older adults: a cross-sectional analysis in five Canadian cities using the CLSA. Journal of Aging and Environment 2020;34:435-54.

83 Chamberlain AM, Finney Rutten LJ, Wilson PM, et al. Correction to: neighborhood socioeconomic disadvantage is associated with multimorbidity in a geographically-defined community. BMC Public Health 2020;20:1412.

84 Vinjerui KH, Bjerkeset O, Bjorngaard JH, et al. Socioeconomic inequalities in the prevalence of complex multimorbidity in a Norwegian population: findings from the cross-sectional HUNT study. BMJ Open 2020;10:e036851.

85 Yildiz B, Schuring M, Knoef MG, et al. Chronic diseases and multimorbidity among unemployed and employed persons in the Netherlands: a register-based cross-sectional study. BMJ Open 2020;10:e035037.

86 Agborsangaya CB, Lau D, Lahtinen M, et al. Multimorbidity prevalence and patterns across socioeconomic determinants: a cross-sectional survey. BMC Public Health 2012;12:201.

87 Antonovsky A, Sourani T. Family sense of coherence and family adaptation. J Marriage Fam 1988;50:79-92.

88 Hill AB. The environment and disease: association or causation? Proc R Soc Med 1965;58:295-300.

89 VanderWeele TJ. Explanation in causal inference : methods for mediation and interaction. New York: Oxford University Press, 2015.

90 Moin JS, Glazier RH, Kuluski K, et al. Examine the association between key determinants identified by the chronic disease indicator framework and multimorbidity by rural and urban settings. J Comorb 2021;11:26335565211028157.

91 Stokes T, Azam M, Noble FD. Multimorbidity in Māori and Pacific patients: cross-sectional study in a Dunedin general practice. J Prim Health Care 2018;10:39-43.

92 Nielsen CR, Halling A, Andersen-Ranberg K. Disparities in multimorbidity across Europe - Findings from the SHARE Survey. Eur Geriatr Med 2017;8:16-21.

93 Congdon P. Area variations in multiple morbidity using a life table methodology. Health Serv Outcomes Res Methodol 2016;16:58-74.

94 Diaz E, Poblador-Pou B, Gimeno-Feliu L-A, et al. Multimorbidity and its patterns according to immigrant origin. A nationwide registerbased study in Norway. PLoS One 2015;10:e0145233.

95 Prazeres F, Santiago L. Prevalence of multimorbidity in the adult population attending primary care in Portugal: a cross-sectional study. BMJ Open 2015;5:e009287.

96 Roberts KC, Rao DP, Bennett TL, et al. Prevalence and patterns of chronic disease multimorbidity and associated determinants in Canada. Health Promot Chronic Dis Prev Can 2015;35:87.

97 Violán C, Foguet-Boreu Q, Fernández-Bertolín S, et al. Soft clustering using real-world data for the identification of multimorbidity patterns in an elderly population: cross-sectional study in a Mediterranean population. BMJ Open 2019;9:e029594. 